\title{
Characterization of Aerodynamically Separated Products of Fly Ash Produced via the Pulverized Combustion of Coal from Kuznetsk Basin
}

\author{
Galina V. Akimochkina, Olga A. Kushnerova, \\ Elena S. Rogovenko and Elena V. Fomenko* \\ Institute of Chemistry and Chemical Technology SB RAS \\ FRC "Krasnoyarsk Science Center SB RAS" \\ 50/24 Akademgorodok, Krasnoyarsk, 660036, Russia
}

Received 19.02.2018, received in revised form 28.02.2018, accepted 04.03.2018

A one-stage aerodynamic separation of fly ash produced via the pulverized combustion of coal from Kuznetsk basin was carried out. Morphologically homogeneous fractions of microspherical particles, with size parameters $-d_{\max }=4,16 u 60 \mu \mathrm{m}$ and $d_{90}=10,40$ u $115 \mu \mathrm{m}$, were recovered. It was found that all obtained fractions have two major chemical components, namely $\mathrm{SiO}_{2}$ (54-63 wt \%) and $\mathrm{Al}_{2} \mathrm{O}_{3}$ (21-29 wt \%). The phase composition includes amorphous component - aluminosilicate glass (81$84 w t \%)$ and crystalline phases - mullite (7-9 wt \%), quartz (4-9 wt \%), hematite (about 2 wt \%) and ferrospinel (about $1 \mathrm{wt} \%$ ). An increase in the $\mathrm{SiO}_{2}$ content and quantity of quartz, as well as a decrease in the $\mathrm{Al}_{2} \mathrm{O}_{3}$ content and quantity of mullite were observed with increasing fraction size.

Keywords: aerodynamic separation, fly ash, homogeneous fractions.

Citation: Akimochkina G.V., Kushnerova O.A., Rogovenko E.S., Fomenko E.V. Characterization of aerodynamically separated products of fly ash produced via the pulverized combustion of coal from Kuznetsk basin, J. Sib. Fed. Univ. Chem., 2018, 11(2), 197-210. DOI: 10.17516/1998-2836-0068.

(c) Siberian Federal University. All rights reserved

* Corresponding author E-mail address: agv3107@mail.ru, mikhaylovaolgaa@mail.ru 


\title{
Характеристика продуктов
}

\section{аэродинамического разделения золы-уноса \\ от пылевидного сжигания угля Кузнецкого бассейна}

\author{
Г.В. Акимочкина, О.А. Кушнерова, \\ Е.С. Роговенко, Е.В. Фоменко \\ Институт химии и химической технологии СО РАН \\ ФИЦ «Красноярский научный центр СО РАН» \\ Россия, 660036, Красноярск, Академгородок, 50/24
}

Аэродинамическим методом выполнено одностадийное разделение золь-уноса от пылевидного сжигания каменного угля Кузнеикого бассейна. Получены морфологически однородные фракиии сферических частии с $d_{\max }=4,16$ и 60 мкм, $d_{90}=10,40$ и 115 мкм. Установлено, что основными компонентами химического состава полученных фракций являются $\mathrm{SiO}_{2}$ и $\mathrm{Al}_{2} \mathrm{O}_{3}$, содержание которых равно 54-63 и 21-29 мас. \% соответственно. Фазовый состав включает стеклофазу в количестве 81-84 мас. \% и кристаллические фазы: муллит - 7-9, квари - 4-9, гематит - 2, феррошпинель - 1 мас. \%. С увеличением размера фракций наблюдается рост содержания $\mathrm{SiO}_{2}$ и снижение $\mathrm{Al}_{2} \mathrm{O}_{3}$, содержание фазы квариа увеличивается, а муллита-снижается.

Ключевые слова: аэродинамическое разделение, зола-уноса, однородная фракция.

\section{Введение}

В результате сжигания углей на тепловых электростанциях Российской Федерации ежегодно образуется около 22 млн т золошлаковых отходов (ЗШО). Целесообразным решением экологических и экономических проблем, связанных с большими объемами ЗШО, является их дальнейшее использование в качестве вторичных ресурсов. Однако утилизация ЗШО в России находится на крайне низком уровне: с 1990 по 2015 г. объем утилизации практически не изменился и колеблется в среднем на уровне 4-6 млн т в год. Общий объем накопленных ЗШО на золоотвалах угольных электростанций оценивается примерно в 1.5 млрд т. По экспертным оценкам, на 2017 г. золоотвалы занимают территорию почти 30 тыс. га. и требуют больших эксплуатационных затрат [1].

Основной вклад (60-95 \%) в суммарный выход ЗШО при пылевидном сжигании угля вносит зола-уноса $[2,3]$. Из-за переменного состава и неконтролируемых свойств золы теплоэнергетики в настоящее время рассматриваются как техногенное сырье низкого технологического уровня. Основные направления утилизации зол-уноса в мире включают традиционное крупнотоннажное использование исходной золы без предварительной классификации в строительной индустрии, сельском хозяйстве, автодорожном строительстве [4-6].

Перспективным направлением утилизации зол-уноса является получение материалов с улучшенными свойствами для различных областей применения. В этом случае необходимым становится соответствие определенным требованиям к размеру частиц золы, ее химическому 
и фазовому составу. Так, применение золыуноса класса F (согласно стандарту ASTM 618) в качестве добавки в бетоны позволяет повысить их прочностные характеристики. Для этих целей успешно применяются золы с частицами размером 0.2-6 мкм, содержащие $\mathrm{SiO}_{2}-53, \mathrm{Al}_{2} \mathrm{O}_{3}-$ 28 мас. \% [7]; $\mathrm{d}_{40}=3$ мкм, $\mathrm{SiO}_{2}-54, \mathrm{Al}_{2} \mathrm{O}_{3}-28$ мас. \% [8]; $\mathrm{d}_{40}=3.4$ мкм и $\mathrm{d}_{40}=10$ мкм, $\mathrm{SiO}_{2}-73$ и $52, \mathrm{Al}_{2} \mathrm{O}_{3}-18$ и 26 мас. \% соответственно [9]. При создании огнестойких панелей с высокими изолирующими свойствами использовалась зола с $\mathrm{d}_{50}=4$ мкм, содержащая $\mathrm{SiO}_{2}$ и $\mathrm{Al}_{2} \mathrm{O}_{3}-58$ и 23 мас. \% соответственно, стеклофазы - до 90 мас. \% [10]. В качестве перспективного наполнителя в полимеры применяется зола со средним размером частиц 4.6 мкм, содержащая $\mathrm{SiO}_{2}-49$, $\mathrm{Al}_{2} \mathrm{O}_{3}-34$ мас. \% [11]. Из золы алюмокремнистого состава с $\mathrm{d}_{\mathrm{cp}}=32$ мкм получены огнестойкие материалы [12], а с $\mathrm{d}_{50}=2.53$ мкм $\left(\mathrm{SiO}_{2}-47, \mathrm{Al}_{2} \mathrm{O}_{3}-41\right.$ мас. \%) - синтезированы керамические мембранные подложки [13]. В производстве однородных и прочных геополимеров показана перспективность использования высококальциевой золы $\left(\mathrm{SiO}_{2}-29, \mathrm{Al}_{2} \mathrm{O}_{3}-13, \mathrm{CaO}-26\right.$ мас. \% c $\mathrm{d}_{\mathrm{cp}}=8.5$ мкм) [14] и золы с высоким содержанием железа $\left(\mathrm{SiO}_{2}-49, \mathrm{Al}_{2} \mathrm{O}_{3}-13, \mathrm{Fe}_{2} \mathrm{O}_{3}-16\right.$ мас. \% $\mathrm{c} \mathrm{d}_{\mathrm{cp}}=13.25$ мкм) [15].

В указанных случаях используется исходная зола с широким распределением частиц по размеру без предварительного разделения. Лишь в единичных работах рассматривается применение зол-уноса, отобранных с полей электрофильтров $[16,17]$. Качественное разделение зол на фракции определенного размера и состава позволит существенно расширить сферы их применения, превратив крупнотоннажные отходы теплоэнергетики в ценное минеральное сырье техногенного происхождения. В последние годы повышенный интерес вызывают разработки на основе отдельных компонентов зол функциональных материалов с заданными свойствами (адсорбентов, катализаторов, носителей, керамических материалов, цеолитов) $[4,6]$. Так, выделение из зол-уноса узких фракций микросфер определенного размера в интервале 50-250 мкм с постоянным химическим и минерально-фазовым составом [18-21] позволило получить высокоселективные мембраны для диффузионного выделения гелия и контейнеры для хранения водорода [22-24], эффективные катализаторы для процессов окисления метана [25, 26], крекинга тяжелой нефти, мазутов и битумов [27, 28], сенсибилизаторы эмульсионных взрывчатых веществ [29], магнитоуправляемые капсулированные $p H$-чувствительные спиновые зонды для исследования биологических объектов [30], магнитные аффинные сорбенты типа «ядрооболочка» для выделения рекомбинантных белков [31, 32], композитные сорбенты для извлечения радионуклидов из жидких радиоактивных отходов [33-35].

Целью работы являлось разделение золы-уноса от пылевидного сжигания кузнецкого угля на однородные фракции и их характеристика, включающая определение насыпной плотности, распределения по размерам, химического и фазового состава. Это позволит использовать зольные фракции в качестве перспективного сырья для получения материалов с улучшенными свойствами, что приведет к снижению общих объемов ЗШО.

\section{Экспериментальная часть}

В качестве сырья для получения узких фракций определенного размера и состава использовали золу-уноса от пылевидного сжигания каменного угля Кузнецкого бассейна технологической марки Т на Московской ТЭЦ-22. Промышленное сжигание угля производилось в котлоагрегатах марки ТПП-210А с жидким шлакоудалением при температуре в центре фа-

$$
-199 \text { - }
$$


кела $\geq 1600{ }^{\circ} \mathrm{C}$. Система пылезолоулавливания включала 4-польный электрофильтр типа FTA с коэффициентом улавливания 99.5-99.8 \%. Отбор проб золы был осуществлен из первого и второго полей электрофильтра (маркировка КТ1 и КТ2 соответственно). Насыпная плотность, характеристики распределения частиц по размеру, химический и фазовый составы зол КТ1 и КТ2 приведены в табл. 1.

Для выделения из золы однородных фракций с определенным максимумом распределения частиц по размеру был использован метод аэродинамического разделения, реализованный на лабораторной установке (рис. 1). Принцип действия заключается в следующем: с помощью насоса (4) создается разрежение, за счет которого поток атмосферного воздуха начинает поступать через трубку (2), оснащенную фильтром, в аэродинамическую трубу (1), проходит через регулятор расхода воздуха (3), насос (4), фильтр (6), затем, очищенный, выбрасывается в атмосферу. В процессе разделения зола загружается в аэродинамическую трубу (1), где в псевдоожиженном слое подвергается действию гравитационных сил и сил аэродинамического сопротивления. В результате крупные и тяжелые частицы золы оседают в нижней части аэродинамической трубы (1), более легкие и мелкие частицы с потоком воздуха поступают на входной фильтр насоса (4), где оседают частицы средней плотности и размера, а самые легкие и мелкие частицы достигают фильтра (6).

Разделение золы осуществлялось партиями объемом $100 \mathrm{~cm}^{3}$ в течение 20 мин при линейной скорости воздушного потока 0.043 м/с. В результате были получены три фракции золы: крупная (КФ), собранная в нижней части аэродинамической трубы, средняя (СФ), поступившая на входной фильтр насоса (4) и выгруженная с помощью штуцера (5), и мелкая (МФ), уловленная фильтром (6) (табл. 2).

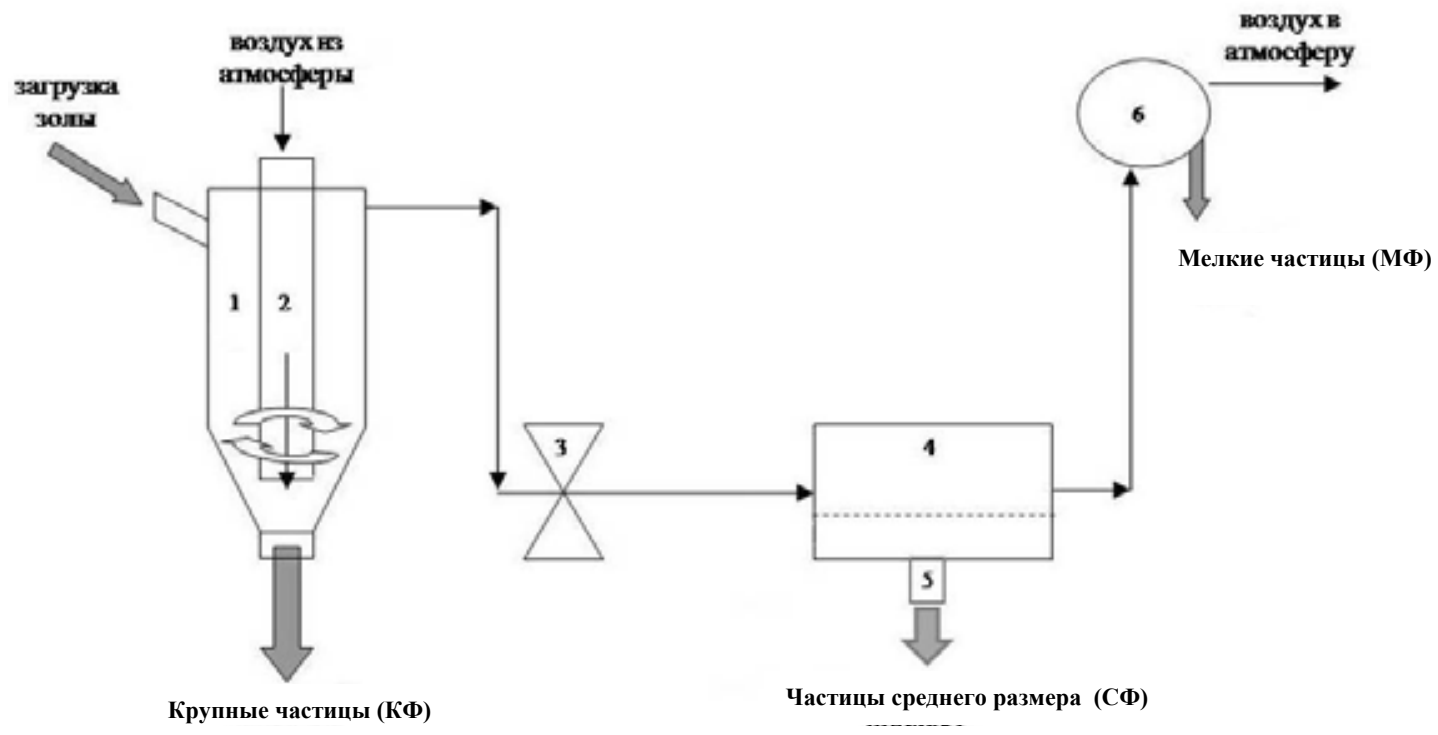

Рис. 1. Схема лабораторной установки для аэродинамического разделения золы-уноса: 1 аэродинамическая труба; 2 - трубка для поступления воздуха; 3 - регулятор расхода воздуха; 4 - насос; 5 - нижний штуцер; 6 - фильтр

Fig. 1. The scheme of laboratory aerodynamic setup for the fly ash separation: 1 - aerodynamic tube; 2 - air feed pipe; 3 - air flow controller; 4 - compressor; 5 - bottom connector; 6 - filter 

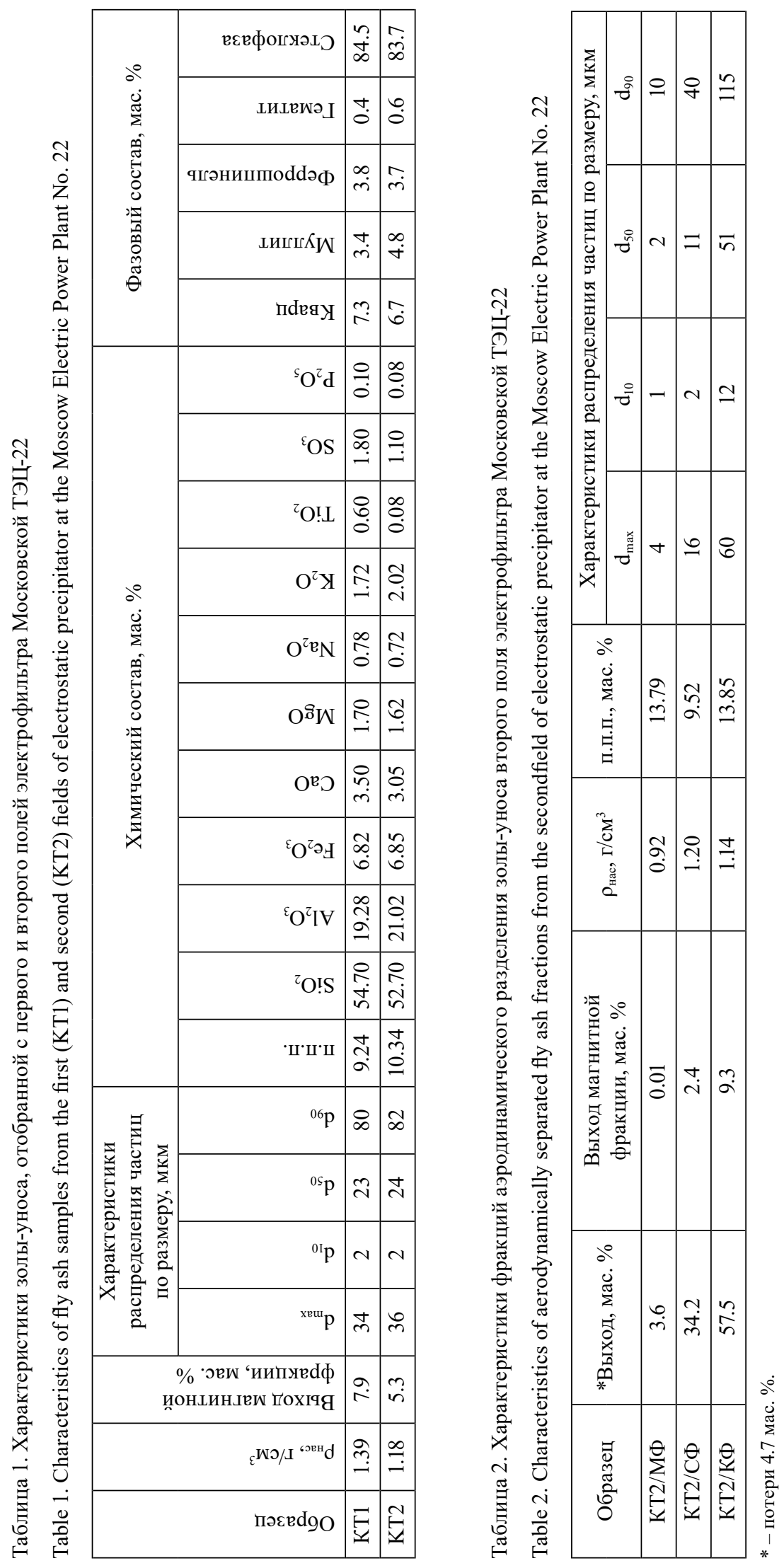
Для полученных фракций золы были определены насыпная плотность и распределение по размерам. Принимая во внимание высокое содержание недожога (п.п.п. 9-14 мас. \%, табл. 2), фракции прокалили при $815^{\circ} \mathrm{C}$ до постоянной массы по методике [36], затем был определен их химический и фазовый состав (табл. 3).

Насыпную плотность определяли на автоматизированном анализаторе Autotap (QuantachromeInstruments, CШA). Распределение частиц по размеру устанавливали на лазерном анализаторе MicroTec 22 (Fritsch, Германия) в мокром режиме с использованием дистиллированной воды и ультразвукового источника, позволяющего разрушать агломераты зольных частиц.

Химический состав, включающий содержание оксидов кремния, алюминия, железа, кальция, магния, калия и натрия, а также потери при прокаливании (п.п.п.), определяли согласно ГОСТ 5382-91 [37]. Фазовый состав выявили с применением полнопрофильного анализа по методу Ритвельда [38] с минимизацией производной разности по методике, применяемой ранее для алюмосиликатных микросфер зол-уноса [21, 22]. Дифракционные данные были получены на порошковом дифрактометре X'PertProMPD (PANalytical, Нидерланды) с твердотельным детектором PIXcel и вторичным графитовым монохроматором для $\mathrm{Cu}_{\mathrm{Ka}}$-излучения.

Исследование морфологии глобул выполняли на порошковых образцах с применением сканирующих электронных микроскопов ТМ-1000 (Hitachi, Япония) и LEO-1430 (CarlZeiss, Германия).

\section{Результаты и обсуждение}

Характеристики исходной золы, отобранной из 1-го (КТ1) и 2-го (КТ2) полей электрофильтра Московской ТЭЦ-22, приведены в табл. 1. Для КТ1 характерно повышенное значение на-

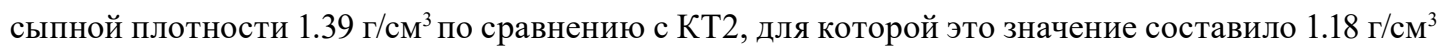
(табл. 1). Содержание магнитной фракции в КТ1 также выше, чем в КТ2 - 8 и 5 мас. \% соответственно. Для обоих образцов наблюдается широкое распределение частиц по размеру (рис. 2) в диапазоне от 0.2 до 250 мкм с $\mathrm{d}_{\max }=34$ и 36 мкм, и $\mathrm{d}_{90}=80$ и 82 мкм соответственно (табл. 1).

Основными компонентами химического состава КТ1 и КТ2 являются $\mathrm{SiO}_{2}$ (55 и 53 мас. \%) и $\mathrm{Al}_{2} \mathrm{O}_{3}$ (19 и 21 мас. \%), суммарное содержание которых составляет около 74 мас. \%. Концентрация $\mathrm{Fe}_{2} \mathrm{O}_{3}$ находится на уровне 7 мас. \%. По данным количественного рентгенофазового анализа (табл. 1), доля аморфной стеклофазы равна 84-85, фазы кварца - около 7, муллита 3-5 мас. \%. На уровне 4 мас. \% присутствует железосодержащая шпинельная фаза, фаза гематита составляет 0.4-0.6 мас. \%. Для КТ1 по сравнению с КТ2 характерно несколько повышенное содержание $\mathrm{SiO}_{2}$ и фазы кварца, а для КТ2 - повышенное содержание $\mathrm{Al}_{2} \mathrm{O}_{3}$ и фазы муллита (табл. 1).

Возможность получения из зол-уноса однородных фракций определенного размера и состава была продемонстрирована на примере золы локального отбора 2-го поля электрофильтра. В результате одностадийного аэродинамического разделения, реализованного на лабораторной установке (рис. 1), были получены три фракции золы: мелкая (КТ2/МФ), средняя (КТ2/СФ) и крупная (КТ2/КФ), выход которых составил 4, 34 и 58 мас. \% соответственно.

Полученные фракции отличаются насыпной плотностью, распределением частиц по размеру, содержанием магнитной составляющей (табл. 2, рис. 3). Фракция КТ2/МФ характери- 


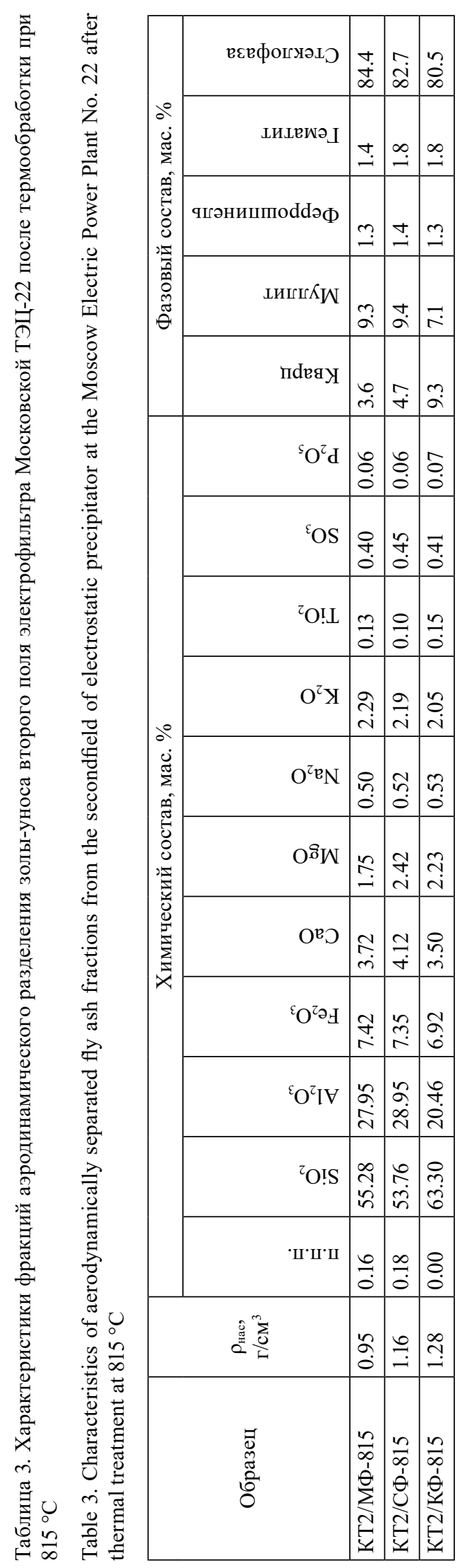




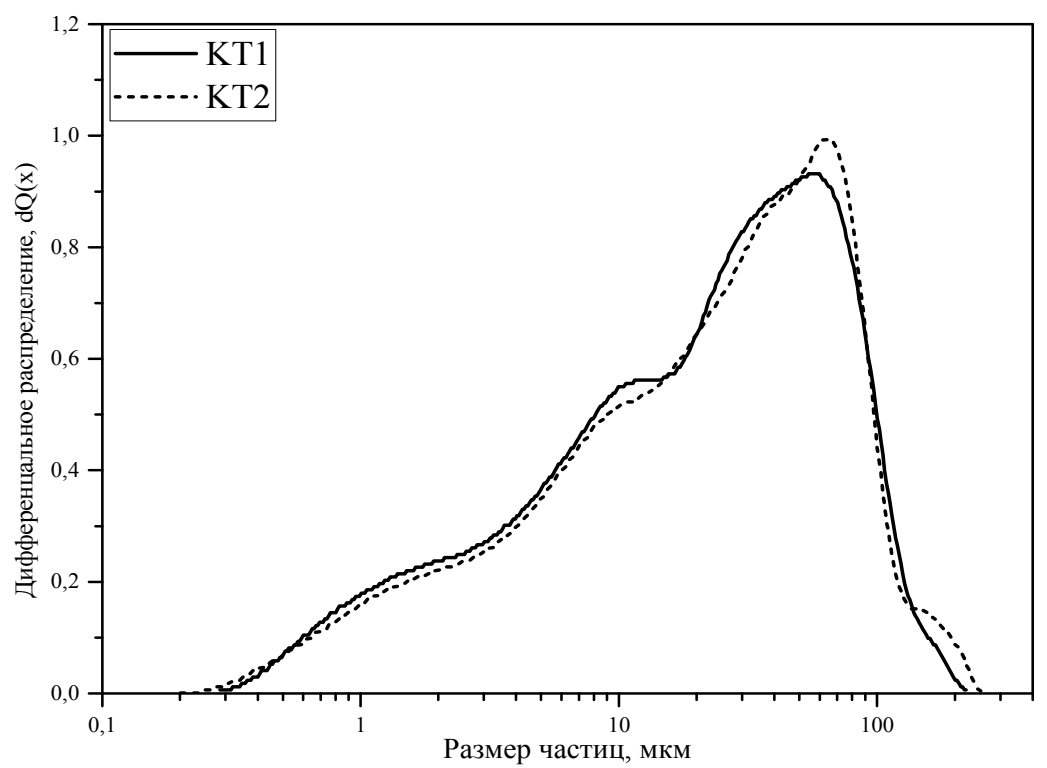

Рис. 2. Дифференциальное распределение частиц по размеру для золы-уноса, отобранной с первого (КТ1) и второго (КТ2) полей электрофильтра Московской ТЭЦ-22

Fig. 2. Differential particle size distribution of fly ash samples from the first (KT1) and second (KT2) fields of electrostatic precipitator at the Moscow Electric Power Plant No. 22

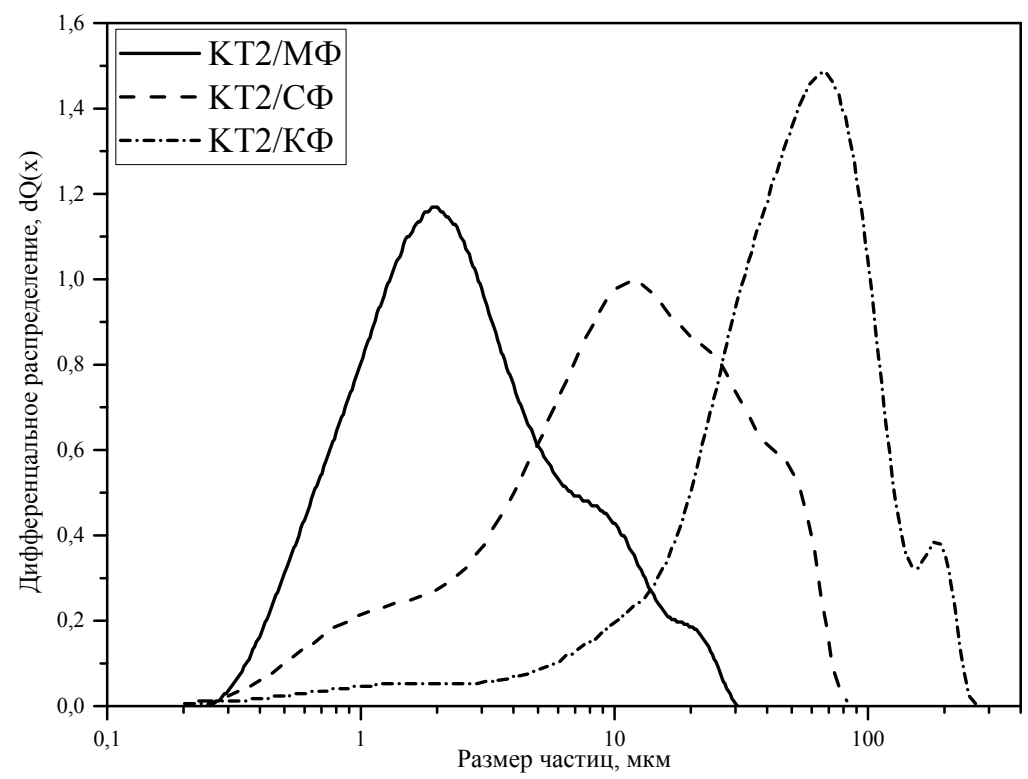

Рис. 3. Дифференциальное распределение частиц по размеру для трех фракций аэродинамического разделения золы-уноса второго поля электрофильтра Московской ТЭЦ-22

Fig. 3. Differential particle size distribution for the three aerodynamically separated fly ash fractions from the secondfield of electrostatic precipitator at the Moscow Electric Power Plant No. 22 
зуется низкой насыпной плотностью 0.92 г $/ \mathrm{cm}^{3}$ и узким распределением частиц по размеру в интервале 0.2-30 мкм с $\mathrm{d}_{\max }=4$ мкм. По сравнению с ней насыпная плотность КТ2/СФ становится больше - 1.20 г/см³ , распределение частиц по размерам - шире, достигая 90 мкм, $\mathrm{d}_{\max }$ увеличивается до 16 мкм. Фракция КТ2/КФ характеризуется насыпной плотностью 1.14 г/см², диапазон размеров частиц увеличивается до 250 мкм, а максимум распределения достигает 60 мкм. Содержание магнитной фракции в этих продуктах составило $0.01 ; 2.4$ и 9.3 мас. \% соответственно (табл. 2).

Для удаления недожога полученные фракции золы были прокалены при $815{ }^{\circ} \mathrm{C}$ до постоянной массы по методике [36]. Потери при прокаливании (п.п.п.) составили 10-14 мас. \% (табл. 2). Насыпная плотность прокаленных продуктов КТ2/МФ-815, КТ2/СФ-815 и КТ2/КФ815 имеет значения $0.95,1.16$ и 1.28 г см $^{3}$ соответственно (табл. 3).

Анализ СЭМ-снимков фракций КТ2/МФ-815, КТ2/СФ-815 и КТ2/КФ-815 показал, что они представлены оплавленными частицами сферической формы различного размера. Легкая фракция в основном содержит мелкие глобулы размером меньше 4 мкм (рис. $4 a$ ). Во фракции средней плотности в достаточном количестве появляются сферы размером около 7-10 мкм (рис. 4б), а в тяжелой фракции для большинства глобул характерен размер 30-50 мкм (рис. 4в).
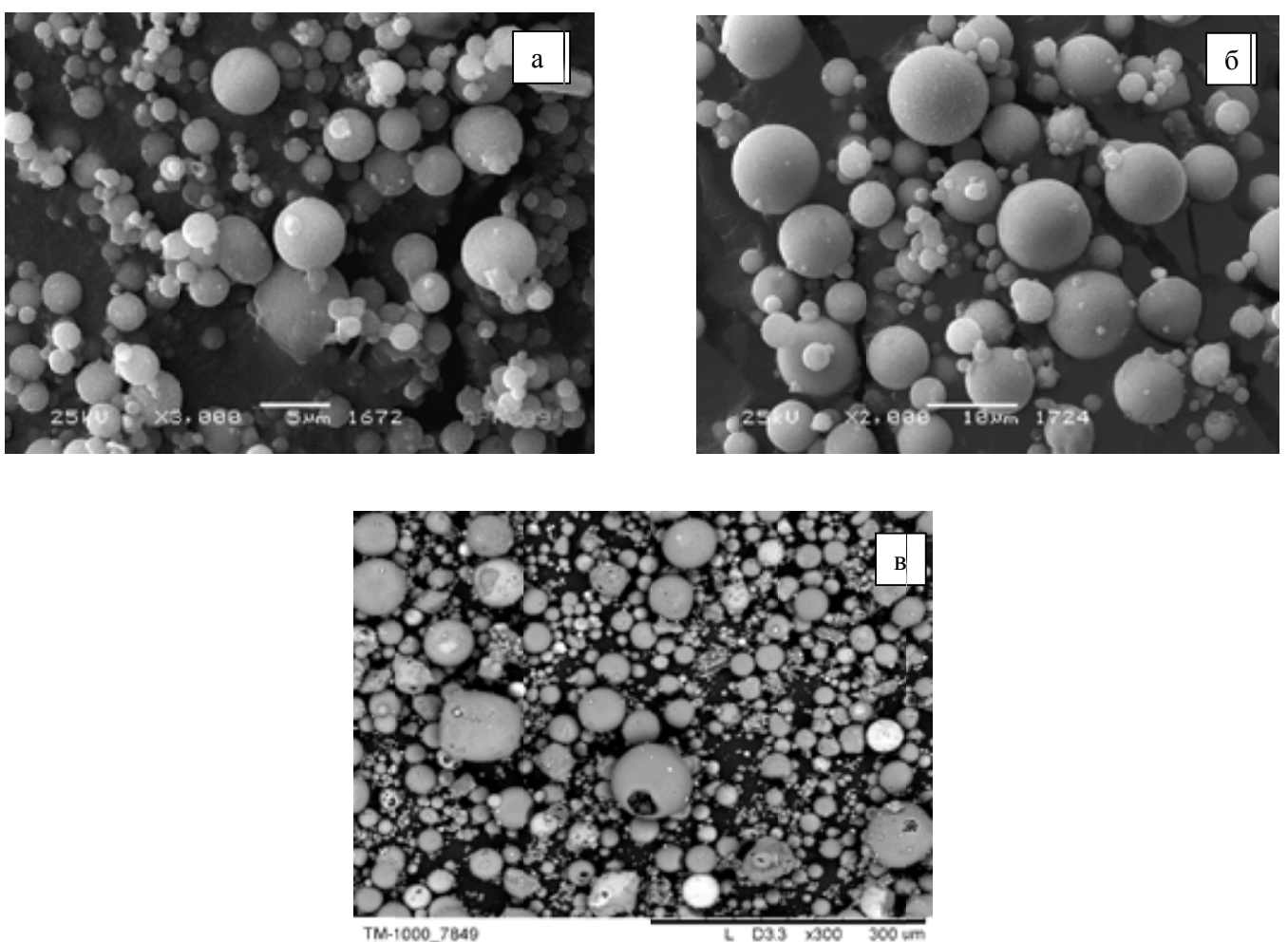

Рис. 4. СЭМ-снимки фракций аэродинамического разделения золы-уноса второго поля электрофильтра Московской ТЭЦ-22 после термообработки при $815^{\circ} \mathrm{C}:$ a - КТ2/МФ-815; б - КТ2/СФ-815; в - КТ2/КФ815

Fig. 4. SEM photo micrographs of aerodynamically separated fly ash fractions from the secondfield of electrostatic precipitator at the Moscow Electric Power Plant No. 22 after thermal treatment at $815{ }^{\circ} \mathrm{C}: \mathrm{a}-\mathrm{KT} 2 /$ MF-815; b - KT2/SF-815; c - KT2/KF-815 
По химическому составу зольные продукты КТ2/МФ-815, КТ2/СФ-815 и КТ2/КФ-815 представляют собой многокомпонентную систему (табл. 3). Содержание основных макрокомпонентов $\mathrm{SiO}_{2}$ и $\mathrm{Al}_{2} \mathrm{O}_{3}$ находится в диапазоне 54-63 и 21-29 мас. \% соответственно, содержание $\mathrm{Fe}_{2} \mathrm{O}_{3}$ составляет около 7 мас. \%. С увеличением размера фракции, проявляющимся в росте $\mathrm{d}_{\max }$ (табл. 2), наблюдается рост содержания $\mathrm{SiO}_{2}$ и снижение $\mathrm{Al}_{2} \mathrm{O}_{3}$ (табл. 3).

Фазовый состав КТ2/МФ-815, КТ2/СФ-815 и КТ2/КФ-815 (табл. 3) включает 81-84 мас. \% стеклофазы и кристаллические фазы: муллит - 7-9, кварц - 4-9, гематит и Fе-содержащая шпинель на уровне 2 и 1 мас. \% соответственно. С ростом размера частиц $\left(\mathrm{d}_{\max }\right.$ во фракции увеличивается) наблюдается увеличение содержания фазы кварца, а количество муллита снижается.

Установленная в данной работе зависимость содержания отдельных компонентов химического и фазового состава от размера фракций аэродинамического разделения золы кузнецкого угля носит обратный характер по сравнению с аналогичными данными для фракций аэродинамического разделения золы экибастузского угля [39]. Так, из золы от пылевидного сжигания каменного экибастузского угля марки СС на Рефтинской ГРЭС аэродинамическим методом были получены узкие фракции, для которых с ростом $\mathrm{d}_{\max }$ от 2 до 116 мкм наблюдается уменьшение содержания $\mathrm{SiO}_{2}$, увеличение количества $\mathrm{Al}_{2} \mathrm{O}_{3}$ и $\mathrm{Fe}_{2} \mathrm{O}_{3}$. В фазовом составе с ростом $\mathrm{d}_{\text {max }}$ в интервале 2-25 мкм наблюдается монотонное снижение концентрации фазы кварца, увеличение муллита и $\mathrm{Fe}$-содержащей шпинельной фазы [39].

Характерная взаимосвязь состава и размера глобул, проявляющаяся для зольных продуктов от сжигания кузнецкого и экибастузского угля в обратных зависимостях, была установлена для узких фракций полых алюмосиликатных микросфер (ценосфер), выделенных из концентратов ценосфер зол-уноса от пылевидного сжигания каменного кузнецкого угля марок Г и Д на Новосибирской ТЭЦ-5 и каменного кузнецкого угля марки Т на Московской ТЭЦ-22 в сравнении с ценосферами, выделенными из концентрата ценосфер золы от сжигания каменного экибастузского угля марки СС на Рефтинской ГРЭС $[21,23]$. Это связано с различными глинистыми минералами исходного угля, принимающими участие в образовании зольных продуктов. При сжигании кузнецкого угля основными прекурсорами являются слоистые минералы иллит-монтмориллонитовой группы, из капель расплава которых образуются мелкие частицы $[18,40]$. В формировании зольных продуктов экибастузского угля, помимо иллита, принимает участие каолинит. Его термохимическое превращение способствует образованию крупных частиц пенистой структуры [21, 41].

Таким образом, в результате одностадийного аэродинамического разделения золы-уноса второго поля электрофильтра Московской ТЭЦ-22 получены и охарактеризованы однородные фракции сферических частиц определенного размера, химического и фазового состава (табл. 2 , 3). Установлены зависимости содержания отдельных компонентов химического и фазового состава от размера частиц. Полученные зольные фракции потенциально пригодны для создания материалов различного назначения с улучшенными свойствами. Сопоставление размера глобул и состава фракций с аналогичными характеристиками успешно используемых на сегодняшний день зольных продуктов позволяет предположить, что легкая и мелкая фракция КТ2/МФ с d $\mathrm{m}_{\max }=4$ мкм, содержащая $\mathrm{SiO}_{2}-55, \mathrm{Al}_{2} \mathrm{O}_{3}-28$ мас. \% (табл. 2, 3), может применяться как добавка в бетоны, повышающая их прочность [7-9], а также для получения огнестойких 
панелей с высокими изолирующими свойствами [10]. Фракция средней плотности и размера КТ2/СФ с d $\mathrm{d}_{\max }=16$ мкм, $\mathrm{SiO}_{2}-54, \mathrm{Al}_{2} \mathrm{O}_{3}-29$ мас. \% найдет применение в производстве прочных и огнестойких геополимеров $[12,17]$. Тяжелая фракция КТ2/КФ, содержащая крупные частицы c $\mathrm{d}_{\max }=60$ мкм, $\mathrm{SiO}_{2}-63, \mathrm{Al}_{2} \mathrm{O}_{3}-20$ мас. \%, перспективна в качестве добавки при получении однородных металлокомпозитов с повышенной твердостью и прочностью [42, 43]. Области применения зольных фракций определенного размера и состава не ограничиваются перечисленными направлениями.

\section{Выводы}

Выполнено одностадийное аэродинамическое разделение золы-уноса от пылевидного сжигания каменного кузнецкого угля марки Т на Московской ТЭЦ-22. Получены морфологически однородные фракции сферических частиц с выходом 4, 34 и 58 мас. \%, отличающиеся насыпной плотностью, размером частиц, химическим и фазовым составом. Для фракции, характеризующейся низкой насыпной плотностью 0.92 г/см³ , наблюдается узкое распределение частиц по размеру в интервале 0.2-30 мкм, $\mathrm{d}_{\max }$ составляет 4 мкм, $\mathrm{d}_{90}=10$ мкм. Для фракции с бо́льшей насыпной плотностью 1.20 г/ $\mathrm{cm}^{3}$ распределение частиц становится шире, достигая 90 мкм, $\mathrm{d}_{\max }=16$ мкм, $\mathrm{d}_{90}=40$ мкм. Фракция с насыпной плотностью 1.14 г/см ${ }^{3}$ содержит частицы размером до 250 мкм, $\mathrm{d}_{\max }=60$ мкм, $\mathrm{d}_{90}=115$ мкм. Установлено, что основными компонентами химического состава полученных фракций являются $\mathrm{SiO}_{2}$ и $\mathrm{Al}_{2} \mathrm{O}_{3}$, суммарное содержание которых достигает 84 мас. \%. Фазовый состав включает стеклофазу в количестве 81-84 мас. \% и кристаллические фазы: муллит - 7-9, кварц - 4-9, гематит - 2, феррошпинель - 1 мас. \%. Установлены зависимости содержания отдельных компонентов химического и фазового состава полученных фракций от размера фракции: с ростом $d_{\max }$ наблюдается рост содержания $\mathrm{SiO}_{2}$ и снижение $\mathrm{Al}_{2} \mathrm{O}_{3}$, содержание фазы кварца увеличивается, а муллита - снижается.

\section{Благодарности}

Авторы выражают благодарность сотрудникам ИХХТ СО РАН Л.А. Соловьевой за проведение количественного рентгенофазового анализа и Е.В. Мазуровой за съемку образцов на сканирующем электронном микроскопе.

\section{Исследование выполнено в рамках проекта фундаментальных исследований СО РАН} V.45.3.3.

\section{Список литературы}

1. Рекомендации «круглого стола» Комитета Государственной Думы по энергетике на тему «О программе экологизации угольной генерации Российской Федерации» [Recommendations of the "round table" of the State Duma Committee on Energy on the theme "On the Program of Greening the Coal Generation of the Russian Federation"]. http://komitet2-13.km.duma. gov.ru/Rabota/Rekomendacii-po-itogam-meropriyatij/item/6278254

2. Drozhzhin V.S., Danilin L.D., Kuvaev M.D., Pikulin I.V., Potemkin G.A., Redyushev S.A., Shpirt M.Ya. Formation processes and main properties of hollow aluminosilicate microspheres in fly ash from thermal power stations. Solid Fuel Chemistry 2008. Vol. 42. No. 2, P. 107-119.

$$
-207 \text { - }
$$


3. Vassilev S.V., Vassileva C.G. Methods for Characterization of Composition of Fly Ashes from Coal-Fired Power Stations: A Critical Overview. Energy and Fuels 2005. Vol. 19(3), P. 1084-1098.

4. Yao Z.T., Ji X.S., Sarker P.K., Tang J.H., Ge L.Q., Xia M.S., Xi Y.Q. A comprehensive review on the applications of coal fly ash. Earth-Science Reviews 2015. Vol. 141, P. 105-121.

5. Ahmaruzzaman M. A review on the utilization of fly ash. Progress in Energy and Combustion Science 2010. Vol. 36(3), P. 327-363.

6. Blissett R.S., Rowson N.A. A review of the multi-component utilisation of coal fly ash. Fuel 2012. Vol. 97, P. 1-23.

7. Fanghui H., Qiang W., Jingjing F. The differences among the roles of ground fly ash in the paste, mortar and concrete. Construction and Building Materials 2015. Vol. 93, P. 172-179.

8. Li Z. Drying shrinkage prediction of paste containing meta-kaolin and ultrafine fly ash for developing ultra-high performance concrete. Materials Today Communications 2016. Vol. 6, P. 74-80.

9. Shaikh F.U.A., Supit S.W.M. Compressive strength and durability properties of high volume fly ash (HVFA) concretes containing ultrafine fly ash (UFFA). Construction and Building Materials 2015. Vol. 82, P. 192-205.

10. Li J., Zhuang X., Leiva C., Cornejo A., Font O., Querol X., Moeno N., Arenas C., Fernández-Pereira C. Potential utilization of FGD gypsum and fly ash from a Chinese power plant for manufacturing fire-resistant panels. Construction and Building Materials 2015. Vol. 95, P. 910-921.

11. Van der Merwe E.M., Prinsloo L.C., Mathebula C.L., Swart H.C., Coetsee E., Doucet F.J. Surface and bulk characterization of an ultrafine South African coal fly ash with reference to polymer applications. Applied Surface Science 2014. Vol. 317, P. 73-83.

12. Zhang H., Kodur V., Cao L., Qi S. Fiber reinforced geopolymers for fire resistance applications. Procedia Engineering 2014. Vol. 71, P. 153-158.

13. Wei Z., Hou J., Zhu Z. High-aluminum fly ash recycling for fabrication of cost-effective ceramic membrane supports. Journal of Alloys and Compounds 2016. Vol. 683, P. 474-480.

14. Phoo-ngernkham T., Chindaprasirt P., Sata V., Hanjitsuwan S., Hatanaka S. The effect of adding nano- $\mathrm{SiO}_{2}$ and nano- $\mathrm{Al}_{2} \mathrm{O}_{3}$ on properties of high calcium fly ash geopolymer cured at ambient temperature. Materials and design 2014. Vol. 55, P. 58-65.

15. Suksiripattanapong C., Horpibulsuk S., Chanprasert P., Sukmak P., Arulrajah A. Compressive strength development in fly ash geopolymer masonry units manufactured from water treatment sludge. Construction and Building Materials 2015. Vol. 82, P. 20-30.

16. Sharonova O.M., Solovyov L.A., Oreshkina N.A., Yumashev V.V., Anshits A.G. Composition of high-calcium fly ash middlings selectively sampled from ash collection facility and prospect of their utilization as component of cementing materials. Fuel processing technology 2010. Vol. 91(6), P. 573-581.

17. Kumar S., Kristály F., Mucsi G. Geopolymerisationbehaviour of size fractioned fly ash. Advanced Powder Technology 2015. Vol. 26(1), P. 24-30.

18. Fomenko E.V., Anshits N.N., Solovyov L.A., Mikhaylova O.A., Anshits A.G. Composition and morphology of fly ash cenospheres produced from the combustion of Kuznetsk coal. Energy and Fuels 2013. Vol. 27(9), P. 5440-5448.

19. Anshits N.N., Mikhailova O.A., Anshits A.G., Salanov A.N. Chemical composition and structure of the shell of fly ash non-perforated cenospheres produced from the combustion of the Kuznetsk coal (Russia). Fuel 2010. Vol. 89(8), P. 1849-1862. 
20. Sharonova O.M., Anshits N.N., Solovyov L.A., Anshits A.G., Salanov A.N. Relationship between composition and structure of globules in narrow fractions of ferrospheres. Fuel 2013. Vol. 111, P. 332-343.

21. Fomenko E.V., Anshits N.N., Vasilieva N.G., Mikhaylova O.A., Rogovenko E.S., Zhizhaev A.M., Anshits A.G. Characterization of fly ash cenospheres produced from the combustion of Ekibastuz coal. Energy and Fuels 2015. Vol. 29(8), P. 5390-5403.

22. Fomenko E.V., Rogovenko E.S., Solovyov L.A., Anshits A.G. Gas permeation properties of hollow glass-crystalline microspheres. RSC Advances 2014. Vol. 4(20), P. 9997-10000.

23. Fomenko E.V., Anshits N.N., Pankova M.V., Mikhaylova O.A., Solovyov L.A., Shishkina N.N., Anshits A.G. Influence of the composition and structure of the glass-crystalline shell of cenospheres on helium permeability. Glass Physics and Chemistry 2012. Vol. 38. No. 2, P. 218-227.

24. Fomenko E.V., Anshits N.N., Solovyov L.A., Vereshchagin S.N., Anshits A.G., Pankova M.V., Fomin V.M. Helium permeability of microspherical membranes based on mullitizedcenospheres. Doklady Physical Chemistry 2010. Vol. 435. No. 2, P. 202-204.

25. Vereshchagin S.N., Rabchevskii E.V., Anshits N.N., Solov'ev L.A., Anshits A.G., Kondratenko E.V. New approach to the preparation of catalysts for the oxidative coupling of methane. Kinetics and Catalysis 2012. Vol. 53. No. 4, P. 449-455.

26. Anshits A.G., Bayukov O.A., Anshits N.N., Rabchevskii E.V., Solovyov L.A., Pletnev O.N., Kondratenko E.V. Catalytic properties and nature of active centers of ferrospheres in oxidative coupling of methane. Applied Catalysis A: General 2016. Vol. 524, P. 192-199.

27. Kopytov M.A., Golovko A.K., Kirik N.P., Anshits A.G. Thermal transformations of highmolecular-mass-components of heavy petroleum residues. Petroleum Chemistry 2013. Vol. 53(1), P. 14-19.

28. Golovko A.K., Kopytov M.A., Sharonova O.M., Kirik N.P., Anshits A.G. Cracking of heavy oils using catalytic additives based on coal fly ash ferrospheres. Catalysis in Industry 2015. Vol. 7. No. 4, P. 293-300.

29. Anshits A.G., Anshits N.N., Deribas A.A., Karakhanov S.M., Plastinin A.V., Sil'vestrov V.V., Kasatkina N.S., Reshetnyak A.Yu. Detonation velocity of emulsion explosives containing cenospheres. Combustion, Explosion, and Shock Waves 2005. Vol. 41. No. 5, P. 591-598.

30. Fomenko E.V., Anshits A.G., Bobko A.A., Khramtsov V.V., Salanov A.N., Kirilyuk I.A., Grigor'ev I.A. Perforatedcenosphere-supportedpH-sensitivespinprobes. Russian Chemical Bulletin 2008. Vol. 57. No. 3, P. 493-498.

31. Vereshchagina T.A., Fedorchak M.A., Sharonova O.M., Fomenko E.V., Shishkina N.N., Zhizhaev A.M., Anshits A.G., Kudryavtsev A.N., Frank L.A. $\mathrm{Ni}^{2+}$-zeolite/ferrosphere and $\mathrm{Ni}^{2+}$-silica/ ferrosphere beads for magnetic affinity separation of histidine-tagged proteins. Dalton Transactions: An International Journal of Inorganic Chemistry 2016. Vol. 45(4), P. 1582-1592.

32. Frank L.A., Borisova V.V., Gitelson I.I., Vereshchagina T.A., Fomenko E.V., Anshits A.G. Affine magnetic sorbents supported on coal ash microspheres for recombinant protein isolation. Applied Biochemistry and Microbiology 2009. Vol. 45. No. 2, P. 215-220.

33. Vereshchagina T.A., Vereshchagin S.N., Shishkina N.N., Solovyov L.A., Mikhaylova O.A., Anshits A.G. One-step fabrication of hollow aluminosilicate microspheres with a composite zeolite/ glass crystalline shell. Microporous and Mesoporous Materials 2013. Vol. 169, P. 207-211. 
34. Vereshchagina T.A., Vereshchagin S.N., Shishkina N.N., Solovyov L.A., Vasilieva N.G., Anshits A.G. Microsphere zeolite materials derived from coal fly ash cenospheres as precursors to mineral-like aluminosilicate hosts for ${ }^{135,137} \mathrm{Cs}$ and ${ }^{90} \mathrm{Sr}$. Journal of Nuclear Materials 2013. Vol. 437, P. 11-18.

35. Панкова М.В., Фоменко Е.В., Аншиц Н.Н., Верещагина Т.А., Аншиц А.Г. Микросферические носители и сорбенты для процессов, протекающих в агрессивных средах. Химия в интересах устойчивого развития 2010. T. 18(5), С. 593-601. [Pankova M.V., Fomenko E.V., Anshits N.N., Vereshchagina T.A., Anshits A.G. Microspherical supports and sorbents for processes in aggressive media.Chemistry for sustainable development 2010. Vol. 18(5), P. 593-601. (In Russ.)]

36. ГОСТ 11022-95 «Топливо твердое минеральное. Методы определения зольности». [GOST 11022-95 “Solidmineralfuels. Methods for determination of ash” (In Russ.)]

37. ГОСТ 5382-91 «Цемент и материалы цементного производства. Методы химического анализа». [GOST 5382-91 “Cements and materials for cement production. Chemical analysis methods" (In Russ.)]

38. Rietveld H.M. A profile refinement method for nuclear and magnetic structures. Journal of Applied Crystallography 1969. Vol. 2, P. 65-71.

39. Kushnerova O.A., Akimochkina G.V., Fomenko E.V., Rabchevskii E.V., Anshits A.G. Onestage aerodynamic separation of fly ash from the pulverized combustion of Ekibastuz basin coal. Solid Fuel Chemistry 2018. V.52. No 3., P. 188-200.

40. Fomenko E.V., Solov'ev L.A., Mikhailova O.A., Anshits N.N., Anshits A.G. Composition and structure of the shells of fly ash cenospheres from the combustion of coal of the Kuznetsk Basin. Solid Fuel Chemistry 2014. Vol. 48. No. 2, P. 129-139.

41. Fomenko E.V., Anshits N.N., Vasil'eva N.G., Rogovenko E.S., Mikhaylova O.A., Mazurova E.V., Solovyev L.A., Anshits A.G. Composition and structure of the shells of aluminosilicate microspheres in fly ash formed on the combustion of Ekibastuz coal. Solid Fuel Chemistry 2016. Vol. 50. No. 4, P. 238-247.

42. Dey A., Pandey K.M. Characterization of fly ash and its reinforcement effect on metal matrix composites: a review. Reviews on Advanced Materials Science 2016. V. 44, P. 168-181.

43. Sudarshan K., Surappa M.K. Synthesis of fly ash particle reinforced A356 Al composites and their characterization. Materials Science and Engineering: A 2008. V. 480, P. 117-124. 